\title{
Revisiting the Potential of Ayurvedic Medicinal Herbs, Neem (Azadirachta indica) and Giloy (Tinospora cordiofolia) for Prevention against COVID-19
}

\author{
Mayank Chaudhary ${ }^{1} \cdot$ Arvind Singh Farswan $^{2} \cdot$ Vivekanand Bahuguna $^{3^{*}}$ \\ ${ }^{1}$ Department of Biotechnology, Maharishi Markandeshwar (Deemed to be) University, Mullana-Ambala- \\ 133207, Haryana, INDIA \\ ${ }^{2}$ College of Pharmacy, Shivalik Campus, Dehradun-248 007, Uttarakhand, INDIA \\ ${ }^{3}$ School of Biological Sciences, Doon University, Dehradun-248012, Uttarakhand, India \\ *Corresponding author: vn1bahuguna@gmail.com
}

Received: 30.11.2021; Revised: 27.12.2021; Accepted: 28.12.2021

(C)Society for Himalayan Action Research and Development

\begin{abstract}
Current pandemic of coronavirus disease 2019 (COVID-19) by severe acute respiratory syndrome coronavirus 2 (SARS-CoV-2) has resulted in huge global mortality with daily increment of cases. Though at present different vaccines are available but complete vaccination at the country level needs subsequent time interval. In present condition of stress and fear, bioactive compounds from different medicinal plants are screened using computational approaches to be used as a potential drug candidate. These in silico approaches have found few phyto-compounds that can be used against therapeutic protein targets of SARS-CoV-2. These natural compounds might have fewer side effects compared to chemotherapeutic agents that are re purposed in this pandemic situation. Though convincing results are obtained from in silico approaches but it warrants further studies to be marketed as a recommended drug. Foreseeing the current pandemic and positive computational results on natural products, these can be considered for enhancing immunity and prevention. Decoction of therapeutically beneficial medicinal plants like neem (Azadirachta indica) and giloy (Tinospora cordiofolia) can be recommended due to easy availability, cost effective nature and easy implementation at community level. These natural products possess anti- inflammatory, antipyretic, fungicidal and antiseptic properties which can prevent from COVID infection and post-COVID complications, including attack from opportunistic pathogens.
\end{abstract}

Keywords: COVID-19, Decoction. Phytocompounds, SARS-CoV-2, Neem, Giloy

\section{Introduction}

COVID-19

Coronavirus (CoV) belongs to Coronaviridae family of RNA viruses (Umakanthan et al. 2020) causing respiratory, gastrointestinal and hepatic diseases in both animals and humans (Weiss and Leibowitz 2011). CoV is responsible for major outbreaks like severe acute respiratory syndrome (SARS) and middle-eastern respiratory syndrome (MERS) over past two decades (Harrison et al. 2020). Out of different genera of $\operatorname{CoV}(\alpha, \beta, \gamma$ and $\delta)$, only $\alpha$ and $\beta$ genera have been reported to infect mammals (Guo et al. 2020). CoV comprises of positive- sense, single stranded RNA genome (Van der Hoek et al. 2004) where 5 ' terminus codes for proteins involved in viral replication and $3^{\prime}$ terminus contains structural proteins. These include spike protein $(\mathrm{S})$, membrane protein $(\mathrm{M})$, envelope protein $(\mathrm{E})$, nucleocapsid protein $(\mathrm{N})$ and haemagglutinin-esterase (HE) protein (Delmas and Laude 1990; Beniac et al. 2006). Interaction between Spike protein $(\mathrm{S})$ of $\mathrm{CoV}$ and human angiotensin converting enzyme 2 (ACE2) receptor mediates attachment and fusion of virus to host cell membrane ( $\mathrm{Li}$ et al. 2003). Initial reports about novel coronavirus came from the Wuhan city of China in December, 2019 (Xu et al. 2020). Severe acute respiratory syndrome coronavirus 2 (SARSCoV-2) was found as the causative agent and 
World Health Organization (WHO) named the disease as coronavirus disease 2019 (COVID19) (Ji et al. 2020). SARS-CoV-2 which belongs to $\beta$ genera of $\mathrm{CoV}$ is an enveloped, non-segmented, positive-sense RNA virus. Genome sequencing results has suspected transfer of SARS-CoV-2 from bats to humans through pangolins (Manis javanica) (Chaudhary 2020). Later on, WHO declared COVID-19 as a pandemic on $11^{\text {th }}$ of March, 2020 and at present it has affected more than 200 countries worldwide. Infection by SARS$\mathrm{CoV}-2$ involves cleavage of $\mathrm{S}$ protein at $\mathrm{S} 1 / \mathrm{S} 2$ protease cleavage site (Wang et al. 2020). S1 subunit causes binding of virus to host cells whereas S2 subunit is critically involved in membrane fusion (Walls et al. 2020). S1 subunit constitutes N-terminal domain (NTD) and receptor binding domain (RBD) whereas S2 comprises of fusion peptide (FP), heptad repeat 1 (HR1), central helix $(\mathrm{CH})$, connector domain (CD), heptad repeat 2 (HR2), transmembrane domain (TD) and cytoplasmic tail (Wang et al. 2020). Upon binding to ACE2, spike protein (S) of SARS undergoes conformational change to be targeted for proteolytic cleavage (Li et al. 2006). Trimming by cathepsin (Simmons et al. 2005) or by type II transmembrane serine proteases (TTSPs) including transmembrane protease serine 2 (TMPRSS2) and human airway trypsin-like protease (HAT) activates spike protein (S) of SARS-CoV (Matsuyama et al. 2010). Abundant expression of ACE2 protein in epithelia of lung and intestine (Hamming et al.
2004) along with mucosa of oral cavity (Xu etal. 2020) provide possible route of entry. Greater infectivity and transmissibility of SARS- CoV-2 is because of its higher binding affinity to ACE2 receptor in comparison to SARS- CoV which caused SARS and MERS (Wrapp et al. 2020; He et al. 2020). This enhanced binding affinity of SARS-CoV-2 for ACE2 is responsible for its ability to target nasopharyngeal and oropharyngeal tissues as abundant expression of ACE2 is found in human mucosal and oral tissues (Hamming et al. 2004; Xu et al. 2020).

SARS-CoV-2 infection manifests flu-like symptoms leading to acute respiratory distress (ARDS), pneumonia, renal failure and death (Harrison et al. 2020). COVID-19 infection is not age restricted so individuals belonging to different age groups are at potential risk (Chao et al. 2020). Initiation of COVID-19 with mild symptoms can culminate in life threatening systemic inflammation and multiorgan damage (Harrison et al. 2020). As of October, 2021, more than 50 lac global deaths due to COVID-19 have been reported and the number of infected individuals is increasing at a rapid pace. In the context of Indian scenario, the death toll crossed 4.5 lac mark making India third most affected nation on the basis of mortality. Though the government is applying strict and appropriate measures to tackle this pandemic with betterment in the medical sector and initiation of vaccination drive but self-care should be employed till complete vaccination is 
achieved. So consumption of natural products and decoction can be considered as a more simple and economical measure at present. With the vast therapeutic potential, medicine systems like Ayurveda and Yoga can prove effective adjuvant therapy of COVID-19 (Golechha 2020).

Ayurveda is a traditional Indian medicine system which originated many thousand years ago. It not only focuses on curing the disease but also prevents development of any illness (Mukherjee et al. 2017). Ayurveda comprises of ayur (life) and veda (science or knowledge). Details about management of epidemic and immunity as critical criteria to either prevent or arrest progression of disease is very well documented in Charaka Samhita which is a classic Ayurveda text (Golechha 2020). Prophylaxis measures like consumption of herbal decoctions and hot water along with gargling and steam inhalation is well described in Ayurveda for respiratory illness (Chandran et al. 2018). These simple and affordable Ayurvedic interventions can be easily implemented on wider scale (Golechha 2020). In India, the Ministry of Ayush released guidelines to boost immunity and self-care by applying Ayurvedic principles (Ministry of Ayush, 2020). As a result of this, many individuals are taking decoctions (Kadha) and following routine practices of gargling with hot water and steam inhalation as a preventive measure against current COVID-19 pandemic. For details about Ayurveda, its history and major
Ayurvedic disciplines along with quality control of Ayurvedic medicines readers are suggested for Mukherjee et al. (2017) as this article focuses on the usage of mentioned natural products as a preventory measure against COVID-19.

\section{Natural Products with Therapeutic Potential}

Medicinal plants contain different phytochemicals with enormous therapeutic potential. Vast research is also focused on extraction of these phytochemicals and exploring their efficacy and action (Fig.1). Different dietary supplements and home-made remedies have great potential to prevent against acute respiratory infections. In addition to prevention, these agents also enhance the immunity to fight against various infectious agents. These home-based remedies harness great therapeutic potential against respiratory infections (Thota et al. 2020). The paper described about the main bioactive compound present in home-based remedies (like ginger, garlic, onion, turmeric, neem, basil, pepper) along with their molecular mechanism. Proteases of SARS- CoV targets TGF- $\beta 1$ (transforming growth factor beta 1) and NF-kB (nuclear factor kappa- light-chainenhancer of activated B cells) for the activation of downstream effector proteins in order to induce fibrosis ( $\mathrm{Li}$ et al. 2012; Kim et al. 2013; Kobayashi et al. 2014) and release of inflammatory cytokines ( $\mathrm{Fu}$ et al. 2020). 
Bioactive compounds from such home-based remedies inhibit the activation of TGF- $\beta 1$ and $\mathrm{NF}-\mathrm{kB}$ as a preventory measure. Current research focuses on computational studies

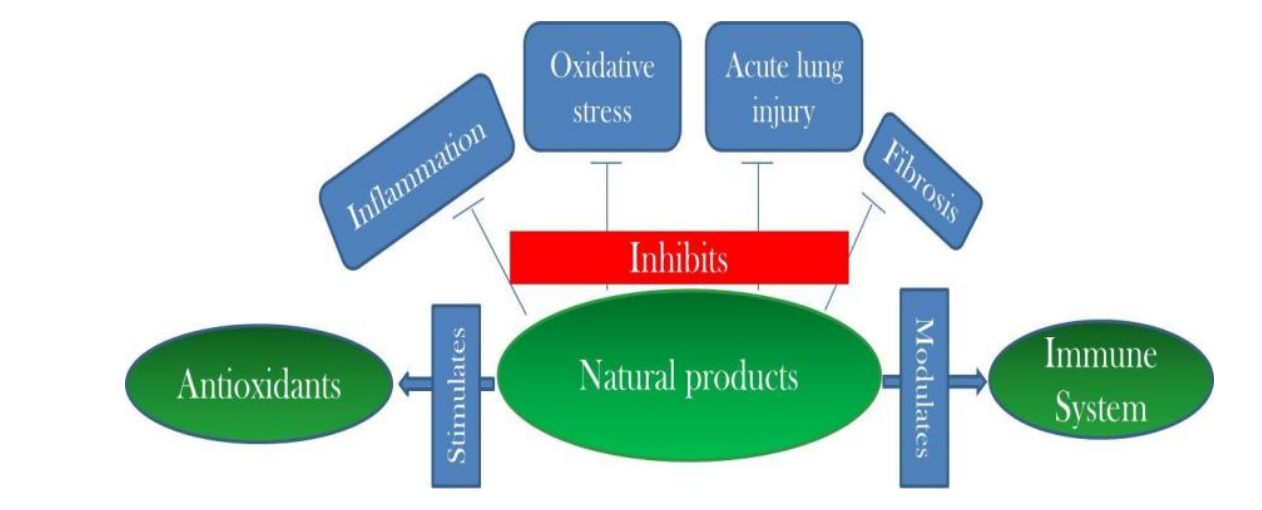

Fig 1 Properties of natural products (adapted from Thota et al. 2020)

\section{Fig 1 Properties of natural products (adapted from Thota et al. 2020)}

targeting molecular docking to select out the best possible phytochemical from different medicinal plants to be used against SARSCoV-2.

\section{Medicinal plants as Potential Candidate}

Neem (Azadirachta indica) and Giloy

\section{(Tinospora cordiofolia)}

Neem (Azadirachta indica) is a precious medicinal plant which has been used to cure many acute and chronic diseases (Gupta et al. 2017). Over hundreds of chemically diverse and structurally complex phytochemicals have been isolated from neem (Subapriya and Nagini 2005). Phytochemicals extracted from different parts of neem are categorized into isoprenoids (like diterpenoids, triterpenoids, limonoids) and non-isoprenoids (like proteins, polysaccharides, polyphenolics, tannins and aliphatic compounds) (Brahmachari 2004). Some of the triterpenoids isolated from neem exhibits vast therapeutic potential including anti-inflammatory, antipyretic, fungicidal and antiseptic properties. Neem and its constituents are found to modulate the regulation of various signalling pathways (Gupta et al. 2017). Some of the targets of neem are those involved in the progression of COVID-19 (Fig.2). The additional potential of neem against diabetes and hypertension along with antifungal properties can be exploited as these have been commonly reported as post- COVID complications in the recovered patients. Both in vivo and in vitro studies highlighting the potential of neem against diabetes and hypertension are available (Gupta et al. 2017). Similar to neem, giloy (Tinospora cordiofolia) is also a well-established Ayurvedic medicinal plant used in traditional Indian system of medicine (ISM) to treat various complications of human body (Sharma et al. 2019). It has huge applicability in enhancing body's resistance power and immunomodulation by improving innate immunity. It possesses anti-inflammatory, analgesic and anti-pyretic activities (Husain et al. 2015; Philip et al. 2018). Giloy possess numerous crucial phytochemical compounds including terpenoids, alkaloids, phenolics, 
lignans and steroids (especially, tinocordiside, tinosporine, diterpenoid) (Singh and Chaudhari 2016; Sharma et al. 2019). These phytocompounds enrich giloy with antioxidant, hypoglycemic, antiviral and immunomodulatory activities. Moreover, different components of giloy like leaves, stem and roots have been found to be effective against variety of diseases (Singh and Chaudhari 2016; Sharma et al. 2019).

Tinospora also possess terpenoids that has huge potential against respiratory tract infections (Sharma et al. 2019; Antul et al. 2019). Further, Tinosporin and diterpenoid has potential role against different subgroups of retroviruses (Singh and Chaudhari, 2016).

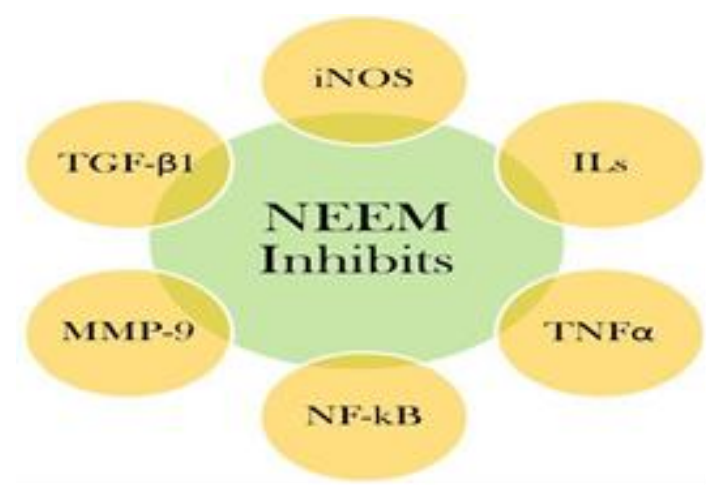

Fig. 2 Potential targets of neem and its constituents

\section{Molecular Docking Studies for Potential Drug Candidate}

During current pandemic different computational approaches like molecular docking, molecular dynamics simulations and others are adopted for screening of potential molecules/drugs from various databases. It also involves screening of phytochemicals from different medicinal plants in search of identifying the most effective compound against therapeutic protein targets of SARSCoV-2. Protein targets of SARS-CoV-2 that are being considered include 3CLpro (chymotrypsin like main protease), PLpro (papain-like protease), SGp-RBD (spike glycoprotein- receptor binding domain), $\mathrm{RdRp}$ (RNA dependant RNA polymerase) and ACE2 (angiotensin-converting enzyme 2) (Vardhan and Sahoo 2020). As a result numerous molecular docking studies are ongoing in order to identify the most potent phytochemical that can be used as an effective anti-viral drug.

ACE2 is the main receptor through which spike (S) protein of SARS-CoV-2 interacts after its trimming by TMPRSS2 (transmembrane protease serine 2). Phytochemicals from neem (Azadirachta indica) and Aloe barbadensis were screened against TMPRSS2 protein using molecular docking study (Senapati et al. 2021). Nimbochalsin from A. indica was found to be the most stable lead compound among others. Similarly, 154 phytochemicals were screened from limonoids and triterpenoids that can show inhibitory effects against SARS-CoV-2. Study involved molecular docking, in silico ADMET and protein-ligand interaction to reduce the number to seven phytochemicals for final screening as potent inhibitors of SARS-CoV-2. Majority of the finally selected phytochemicals screened against therapeutic protein targets of SARS-CoV-2 proved effective against each of the therapeutic target protein with glycyrrhizic acid as the most potent phytochemical targeting active site of 
all the studied protein targets (Vardhan and Sahoo 2020). Identical to these, another study aimed to find an effective plant- based treatment for COVID-19 screened 38 bioactive compounds from five different plant sources including A. indica. These compounds were subjected to molecular docking against the main protease of SARS-CoV-2. Out of all the studied compounds, gedunin was found to be comparatively most potent (Garg et al. 2020). Another study by Adegbola et al. (2021) screened compounds from three plants against proteins of SARS-CoV-2 including PLpro (papain like protease), 3CLpro (chymotrypsin like main protease) and TMPRSS2. The study found various compounds from A. indica as potential drug candidates possessing good pharmacokinetics and toxicity profile. Similarly, Ogidigo et al. (2020) screened natural phytochemicals from $A$. indica and Momordica charantia L. as possible inhibitors against SARS-CoV-2 protease. Their study compared the inhibition potential of selected phytochemicals with food and drug administration (FDA) approved reference antiviral drugs. Other molecular docking studies have also screened compounds from neem and other plants as suitable candidates against SARS-CoV-2 (Borkotoky and Banerjee, 2020;

Baildya et al. 2021; Gogoi et al. 2021).

Similarly, in context of current scenario, molecular docking studies have also found convincing results on therapeutic potential of phytochemicals from giloy. Tinocordiside (phytocompound from Tinospora) was found to be effective against ACE2-RBD complex.
This highlighted the fact that Tinocordiside can prevent entry of SARS-CoV-2 into the host cell by interrupting the interaction between receptor binding domain (RBD) of virus and host ACE2 receptor (Balkrishna et al. 2021a). Inhibitory potential of Tinocordiside against SARS- CoV-2 was further found by Shree et al. (2020) in addition to five other potential phytocompounds from Ashwagandha (Withania somnifera) and Tulsi (Ocimum sanctum). Further, in silico study using molecular docking was done to identify the interaction of constituents of giloy (berberine, $\quad \beta$-sitosterol, $\quad$ coline, tetrahydropalmatine, octacosanol) with 3CLpro (protease of COVID-19 virus) to identify most suitable anti-viral compound (Chowdhury 2020). The study revealed berberine as the most potent phytocompound to target viral replication. In addition to these molecular docking studies, aqueous extract of T. cordiofolia in form of Giloy Ghanvati reversed the damage caused by introduction of spike protein of SARS-CoV-2 in humanized zebrafish model (Balkrishna 2021b). Experimental design involved humanization of zebrafish by transplantation of A549 cells into the swim bladder with subsequent induction of recombinant spike protein of SARS-CoV-2 at the site ofA549 cell xenograft to manifest disease phenotype. Oral infusion of Giloy Ghanvati reversed infiltration of pro-inflammatory immune cells, renal damage and abnormal behavioural fever in the treated group (Balkrishna 2021b). This study validated the results of molecular 
docking studies showing therapeutic potential of giloy against current pandemic.

Though most of the molecular docking studies found phyto-compounds as potential drug candidates, but all these computational results warrants both in vitro and in vivo studies to determine effectiveness of identified compounds as a potent cure for COVID-19. Moreover, such molecular docking results hints on the use of decoction as a preventory measure. It is cheap, more accessible and can be implemented easily in homes by the time efficacy of any such plant based drug is proved through clinical trials before being marketed which requires a considerable amount of time.

\section{Decoction of Neem and Giloy in COVID and Post-COVID Time}

With rapid spread of COVID-19 and limitations of ongoing vaccination drive, prevention should be a priority. Prevention from COVID-19 can be achieved by following proper guidelines from concerned governmental authorities that includes wearing of mask, regular washing of hands and social distancing. In addition to these measures, focus should also be on individual immunity. AYUSH ministry has launched specific guidelines to enhance immunity. In lieu of that certain steps can be taken by individuals at home level in improving their immunity to fight infection. As we have seen that a number of natural products and home-based remedies have great therapeutic potential. Along with this, number of phyto-compounds from $A$. indica and T. cordiofolia has proved effective against SARS-CoV-2 through computational studies. Keeping these things in mind and easy availability of neem (A. indica) and giloy ( $T$. cordiofolia) in Indian sub-continent, consumption of decoction (kadha)of these two can be effective in enhancing immunity and preventing infection. Consumption of decoction of neem and giloy can further prevent from certain post-COVID complications like hypertension, diabetes and body pains as these have been found to be effective against hypertension and diabetes (Gupta et al. 2017) in addition to other complications (Subapriya and Nagini 2005; Chowdhury 2020). So the combination of these can be a suitable preventory method, both during and post-COVID tenure.

Recently, incidence of mucormycosis has also been reported in COVID-19 patients, though the epidemiological factors and outcome is not well described at present (John et al. 2021). Critical COVID-19 patients require ventilatory support, use of corticosteroids and other adjunctive therapies. Long term use of steroid therapy can predispose patients to secondary bacterial and fungal infections. Conditions like uncontrolled diabetes mellitus, immunosuppression and corticosteroid therapy are potential risk factors for mucormycosis infection (Yusuf and Onyiriuka 2009; Ahmadikia et al. 2021). Though at present mucormycosis has become a point of focus, but COVID-19 patients are also prone to Aspergillosis, Candidiasis and Cryptococcosis (Song et al. 2020). Thus, focus should be more on prevention from such opportunistic 
pathogens which might show clinical manifestation as a consequence of current therapy.

It is a point of discussion whether such opportunistic fungal pathogens are affecting due to long term use of steroid therapy or due to some other yet unidentified factor. But considering this, primary focus should be on the use of medicinal plants because consumption of Amphotericin B (presently recommended) for treatment of mucormycosis might lead to some other clinical manifestation. As a result, neem leaves which also possess antifungal properties (Subapriya and Nagini 2005) can be consumed with giloy in the form of decoction possessing vast therapeutic benefits. Thus, combination of these as decoction can be used both for prevention and during the course of COVID infection to keep such opportunistic pathogens at bay.

\section{Conclusion}

COVID-19 is responsible for respiratory tract infection, pulmonary fibrosis and multiple organ damage. Prevention from progression of infection and stabilization of initial symptoms could be achieved by consumption of natural products. Thus, natural products could act as beneficial supplements in the recovery of COVID-19 patients having pulmonary infection. Adverse side effects of drugs (antimalarial, retroviral drugs and corticosteroids) that are being repurposed in current pandemic have been reported in some clinical settings. Seeing the therapeutic potential of many natural products, these can be co-administered to reduce treatmentrelated side effects as they have no adverse effects compared to chemotherapeutic supplements. Different phytochemicals from neem and giloy have shown potential as a probable drug candidate through computational studies and knowing about vast therapeutic benefits of both, decoction of these can be used for prevention and recovery from COVID-19 by the time further research is done on their efficacy through clinical trials. These natural products with no side effect can help in preventing the complications of the ongoing treatment regime. These can additionally prevent from opportunistic pathogens that might show clinical manifestation as a consequence of current therapies. Thus, decoction of neem and giloy can be recommended due to easy availability, inexpensive nature and easy implementation on a community wide-scale.

\section{Acknowledgements}

The authors are thankful to the respective Institutions. No funding was obtained to draft this review article.

\section{References}

Adegbola PI, Semire B, Fadahunsi OS, Adegoke AE (2021) Molecular docking and ADMET studies of Allium cepa, Azadirachta indica and Xylopiaaethiopica isolates as potential anti- viral drugs for Covid-19. Virus 
disease 32: 85-97.

Ahmadikia K, Hashemi SJ, Khodavaisy S, Getso MI, Alijani N, Badali H, et al (2021) The double-edged sword of systemic corticosteroid therapy in viral pneumonia: A case report and comparative review of influenzaassociated mucormycosis versus COVID-19 associated mucormycosis. Mycoses 64: 798-808.

Antul K, Amandeep P, Gurwinder S, Anuj C (2019) Review on pharmacological profile of medicinal vine: Tinospora cordiofolia. Current Journal of Applied Science and Technology 35: 1-11.

Baildya N, Khan AA, Ghosh NN, Dutta T, Chattopadhyay AP (2021) Screening of potential drug from Azadirachta indica (neem) extracts for SARS-CoV2: An insight from molecular docking and MD-simulation studies. J. Mol. Struct. 1227: 129390.

Balkrishna A, Pokhrel S, Varshney A (2021a) Tinocordiside from Tinospora cordiofolia (Giloy) may curb SARS$\mathrm{CoV}-2$ contagion by disrupting the electrostatic interactions between host ACE2 and viral S-protein receptor binding domain. Combinatorial Chemistry and High Throughput Screening 24: 1795-1802.

Balkrishna A, Khandrika L, Varshney A (2021b) Giloy Ghanvati (Tinnospora cordiofolia (Willd.) Hook. f. and Thomson) reversed SARS-CoV-2 viral spike-protein induced disease phenotype in the xenotransplant model of humanized zebrafish. Front. Pharmacol. 12: 635510 .

Beniac DR, Andonov A, Grudeski E, Booth TF (2006) Architecture of the SARS coronavirus prefusion spike. Nat. Struct. Mol. Biol. 13: 751-752.

Borkotoky S, Banerjee M (2021) A computational prediction of SARSCoV-2 structural protein inhibitors from Azadirachta indica (Neem). J. Biomol. Struct. Dyn. 39: 4111-4121.

Brahmachari G (2004) Neem- an omnipotent plant: A Retrospection. ChemBioChem. 5: 408- 421.

Chandran S, Dinesh KS, Patgiri BJ, Dharmarajan P (2018) Unique contributions of Keraleeya Ayurveda in pediatric health care. J. Ayurveda Integr. Med. 9: 136-142.

Chao JY, Derespina KR, Herold BC, Goldman DL, Aldrich M, Weingarten $\mathrm{J}$, et al (2020) Clinical characteristics and outcomes of hospitalized and critically III children and adolescents with coronavirus disease 2019 at a tertiary medical center in New York city. J. Pediatr. 223: 14-19.

Chaudhary M (2020) COVID-19 
susceptibility: potential of ACE2 polymorphisms. Egypt J. Med. Hum. Genet.21: 54.

Chowdhury P (2020) In silico investigation of phytoconstituents from Indian medicinal herb "Tinospora cordiofolia" (giloy) against SARS-CoV-2 (COVID-19) by molecular dynamics approach. J. Biomol. Struct. Dyn. 7: 1-18.

Delmas B, Laude H (1990) Assembly of coronavirus spike protein into trimers and its role in epitope expression. J. Virol. 64: 5367-5375.

Fu Y, Cheng Y, Wu Y (2020) Understanding SARS-CoV-2-mediated inflammatory responses: From mechanisms to potential therapeutic tools. Virol. Sin. 35: 266-271.

Garg S, Anand A, Lamba Y, Roy A (2020) Molecular docking analysis of selected phytochemicals against SARS-CoV-2 Mpro receptor. Vegetos 33: 766-781.

Gogoi B, Chowdhury P, Goswami N, Gogoi N, Naiya T, Chetia P, Mahanta S, Chetia D, Tanti B, Borah P, Handique PJ (2021) Identification of potential plantbased inhibitor against viral proteases of SARS-CoV-2 through molecular docking, MM-PBSA binding energy calculations and molecular dynamics simulation. Molecular Diversity 15: 115.
Golechha M (2020) Time to realise the true potential of Ayurveda against COVID19. Brain Behav. Immun. 87: 130-131.

Guo YR, Cao QD, Hong ZS, Tan YY, Chen SD, Jin HJ, Tan KS, Wang DY, Yan Y (2020) The origin, transmission and clinical therapies on coronavirus disease 2019 (COVID-19) outbreak- an update on thestatus. Mil. Med. Res. 7: 11.

Gupta SC, Prasad S, Tyagi AK, Kunnumakkara AB, Aggarwal BB (2017) Neem (Azadirachta indica): An Indian traditional panacea with modern molecular basis. Phytomedicine 34: 1420.

Hamming I, Timens W, Bulthuis MLC, Lely AT, Navis GJ, van Goor H (2004) Tissue distribution of ACE2 protein, the functional receptor for SARS coronavirus. A first step in understanding SARS pathogenesis. J. Pathol. 203: 631-637.

Harrison AG, Lin T, Wang P (2020) Mechanisms of SARS-CoV-2 transmission and pathogenesis. Trends Immunol. 41: 1100-1115.

He J, Tao H, Yan Y, Huang SY, Xiao Y (2020) Molecular mechanism of evolution and human infection with SARS-CoV-2. Viruses 12: 428.

Husain L, Akash MSH, Ain N-U, Rehman K, Ibrahim M (2015) The analgesic, Anti- 
inflammatory and anti- pyretic activities of Tinospora cardiofolia. Adv. Clin. Exp. Med. 24: 957-964.

Ji W, Wang W, Zhao X, Zai J, Li X (2020) Cross-species transmission of the newly identified coronavirus 2019-nCoV. J. Med. Virol. 92: 433-440.

John TM, Jacob CN, Kontoyiannis DP (2021) When uncontrolled diabetes mellitus and severe COVID-19 converge: The perfect storm for mucormycosis. J. Fungi 7: 298.

Kim SR, Jung YR, An HJ, Kim DH, Jang EJ, Choi YJ, Moon KM, Park MH, Park $\mathrm{CH}$, Chung KW, Bae HR, Choi YW, Kim ND, Chung HY (2013) Antiwrinkle and anti- inflammatory effects of active garlic components and the inhibition of MMPs via NF-kB signalling. PLoS One 8: e73877.

Kobayashi T, Kim HJ, Liu X, Sugiura H, Kohyama T, Fang Q, Wen FQ, Abe S, Wang X, Atkinson JJ, Shipley JM, Senior RM, Rennard SI (2014) Matrix metalloproteinase- 9 activates TGF- $\beta$ and stimulates fibroblast contraction of collagen gels. Am. J. Physiol. Lung Cell Mol. Physiol. 306: L1006-L1015.

Li F, Berardi M, Li W, Farzan M, Dormitzer PR, Harrison SC (2006) Conformational states of the severe acute respiratory syndrome coronavirus spike protein ectodomain. J. Virol. 80: 6794-6800.
Li SW, Yang TC, Wan L, Lin YJ, Tsai FJ, Lai CC, Lin CW (2012) Correlation between TGF- $\beta 1$ expression and proteomic profiling induced by severe acute respiratory syndrome coronavirus papain-like protease. Proteomics 12: 3193-3205.

Li W, Moore MJ, Vasilieva N, Sui J, Wong SK, Berne MA, et al (2003) Angiotensin converting enzyme 2 is a functional receptor for the SARS coronavirus. Nature 426(6965): 450-454.

Matsuyama S, Nagata N, Shirato K, Kawase M, Takeda M, Taguchi F (2010) Efficient activation of the severe acute respiratory syndrome coronavirus spike protein by the transmembrane protease TMPRSS2. J. Virol. 84: 12658-12664.

Ministry of Ayush, Government of India (2020). Ayurveda's immunity boosting measures for self-care during COVID19 crisis.

Mukherjee PK, Harwansh RK, Bahadur S, Banerjee S, Kar A, Chanda J, Biswas S, Ahmmed SKM, Katiyar CK (2017) Development of Ayurveda- Tradition to trend. J. Ethnopharmacol. 197: 10-24.

Ogidigo JO, Iwuchukwu EA, Ibeji CU, Okpalefe O, Soliman MES (2020) Natural phyto compounds as possible non-covalent inhibitors against SARSCoV2 protease: computational approach. J. Biomol. Struct. Dyn. DOI: 
$10.1080 / 07391102.2020 .1837681$

Philip S, Tom G, Vasumathi AV (2018)

Evaluation of the anti-inflammatory activity of Tinospora cardiofolia (Willd.) Miers chloroform extract- a preclinical study. J. Pharm. Pharmacol. 70: 1113-1125.

Senapati S, Banerjee $\mathrm{P}$, Bhagavatula S, Kushwaha PP, Kumar S (2021) Contributions of human ACE2 and TMPRSS2 in determining hostpathogen interaction of COVID-19. J. Genet. 100: 12.

Sharma P, Dwivedee BP, Bisht D, Dash AK, Kumar D (2019) The chemical constituents and diverse pharmacological importance of Tinospora cordiofolia. Heliyon 5: e02437.

Shree P, Mishra P, Selvaraj C, Singh SK, Chaube R, Garg N, et al (2020) Targeting COVID- 19 (SARS- CoV-2) main protease through active phytochemicals of ayurvedic medicinal plants- Withania somnifera (Ashwagandha), Tinospora cordiofolia (Giloy) and Ocimum sanctum (Tulsi)- a molecular docking study. J. Biomol. Struct. Dyn. 27: 1-14.

Simmons G, Gosalia DN, Rennekamp AJ, Reeves JD, Diamond SL, Bates P (2005) Inhibitors of Cathepsin L prevent severe acute respiratory syndrome coronavirus entry. Proc. Natl. Acad. Sci. 102: 11876-11881.

Singh D, Chaudhari PK (2016) Chemistry and pharmacology of Tinospora cordiofolia. Nat. Prod. Commun. 12: 299-308.

Song G, Liang G, Liu W (2020) Fungal coinfections associated with global COVID-19 pandemic: A clinical and diagnostic perspective from China. Mycopathologia 185: 599-606. Subapriya R, Nagini S (2005) Medicinal properties of neem leaves: a review. Curr. Med. Chem. Anticancer Agents 5: 149-156.

Thota SM, Balan V, Sivaramakrishnan V (2020) Natural products as home-based prophylactic and symptom management agents in the setting of COVID-19. Phytother. Res. 34: 3148-3167.

Umakanthan S, Sahu P, Ranade AV, Bukelo MM, Rao JS, Abrahao-Machado LF, et al (2020) Origin, transmission, diagnosis and management of coronavirus disease 2019 (COVID-19). Postgrad. Med. J. 96: 753-758.

Van der Hoek L, Pyrc K, Jebbink MF, Vermeulen-Oost W, Berkhout RJM, Wolthers KC, et al (2004) Identification of a new human coronavirus. Nat. Med. 10: $368-373$.

Vardhan S, Sahoo SK (2020) In silico ADMET and molecular docking study 
on searching potential inhibitors from limonoids and triterpenoids for COVID19. Comput. Biol. Med. 124: 103936.

Walls AC, Park YJ, Tortorici MA, Wall A, McGuire AT, Veesler D (2020) Structure, function and antigenicity of the SARS-CoV-2 spike glycoprotein. Cell 181: 281-292.

Wang MY, Zhao R, Gao LJ, Gao XF, Wang DP, Cao JM (2020) SARS-CoV-2: Structure, biology and structure based therapeutics development. Front. Cell Infect. Microbiol. 10: 587269.

Weiss SR, Leibowitz JL (2011) Coronavirus pathogenesis. Adv. Virus Res. 81: 85164.

Wrapp D, Wang N, Corbett KS, Goldsmith JA, Hsieh CL, Abiona O, et al (2020) Cryo-EM structure of the 2019-nCoV spike in the prefusion conformation. Science 367: 1260-1263.

Xu H, Zhong L, Deng J, Peng J, Dan H, Zeng X, Li T, Chen Q (2020) High expression of ACE2 receptor of 2019-nCoV on the epithelial cells of oral mucosa. Int. J. Oral Sci. 12: 8.

Xu X, Chen P, Wang J, Feng J, Zhou H, Li X, Zhong W, Hao P (2020) Evolution of the novel coronavirus from the ongoing Wuhan outbreak and modelling of its spike protein for risk of human transmission. Sci. China Life Sci. 63:
$457-460$

Yusuf EO, Onyiriuka AN (2009) Subcutaneous Mucormycosis in an Immunocompetent Nigerian Child. Turk. J. Med. Sci. 39: 309-311. 